\title{
BMJ Open Knowledge on neonatal jaundice and its associated factors among mothers in northern Ethiopia: a facility-based cross- sectional study
}

\author{
Asmamaw Demis (D) , ${ }^{1}$ Addisu Getie (D) , ${ }^{1}$ Adam Wondmieneh (D) , \\ Birhan Alemnew (D) , ${ }^{2}$ Getnet Gedefaw ${ }^{3}$
}

To cite: Demis A, Getie A, Wondmieneh A, et al. Knowledge on neonatal jaundice and its associated factors among mothers in northern Ethiopia: a facility-based crosssectional study. BMJ Open 2021;11:e044390. doi:10.1136/ bmjopen-2020-044390

- Prepublication history for this paper is available online. To view these files, please visit the journal online (http://dx.doi. org/10.1136/bmjopen-2020044390).

Received 01 September 2020 Revised 04 February 2021 Accepted 15 February 2021

D) Check for updates

(c) Author(s) (or their employer(s)) 2021. Re-use permitted under CC BY-NC. No commercial re-use. See rights and permissions. Published by BMJ.

${ }^{1}$ Department of Nursing, College of Health Sciences, Woldia University, Woldia, Ethiopia ${ }^{2}$ Department of Medical Laboratory Science, College of Health Sciences, Woldia University, Woldia, Ethiopia ${ }^{3}$ Department of Midwifery, College of Health Sciences, Woldia University, Woldia, Ethiopia

Correspondence to Asmamaw Demis; asmamawdemis@gmail.com

\section{ABSTRACT}

Objective This study aimed to assess mother's

knowledge on neonatal jaundice (NNJ) and its associated factors in northern Ethiopia.

Design Facility-based cross-sectional study.

Setting Referral hospitals in Amhara region, Ethiopia.

Participants The study was done among 380 mothers

selected using a systematic random sampling technique at referral hospitals in the Amhara region, northern Ethiopia, from 1 March 2019 to 30 July 2019.

Primary outcome Mother's knowledge on NNJ, modelled using binary logistic regression.

Secondary outcome Factors associated with mother's knowledge about NNJ

Results This study revealed that the overall mother's knowledge on NNJ was $39.2 \%$. Having favourable attitude (AOR=2.05, 95\% Cl: 1.25 to 3.34), having a history of NNJ in previous children ( $\mathrm{AOR}=7.51,95 \% \mathrm{Cl}: 3.12$ to 18.05$)$, having a history of NNJ in the current child (AOR=1.97, $95 \% \mathrm{Cl}: 1.19$ to 3.27), antenatal care (ANC) follow-up (AOR=3.85, 95\% Cl: 1.24 to 14.55) and resided in the urban area $(A O R=2.63,95 \% \mathrm{Cl}: 1.32$ to 5.25$)$ were factors significantly associated with mother's knowledge on NNJ. Conclusions This study showed that mothers' knowledge on NNJ was low. The attitude of mothers on NNJ, previous and current child history of NNJ, ANC followup and residence were variables that had a significant association with mother's knowledge on NNJ. Enhancing NNJ educational programmes targeting mothers in raising awareness on the prevention of NNJ in the population are the recommended interventions.

\section{INTRODUCTION}

Neonatal jaundice (NNJ) is a yellowish discolouration of the skin and sclera of the newborn as a consequence of increased levels of serum bilirubin affecting more than $50 \%$ of full-term neonates and $80 \%$ of preterm neonates in the first days of their life. ${ }^{1}$ Severe NNJ remains a life-threatening condition in many areas of the world, although the true dimension of the problem is largely unknown. $^{2}$ Worldwide in 2016, more than 2.6 million newborns died, out of this half
Strengths and limitations of this study

- As a strength, the study addresses five referral hospitals in northern Ethiopia

- The study results were presented using appropriate statistical methods

- Due to the cross-sectional nature of the study design, we are unable to establish cause-effect relationships.

- This study could count and credited as being a regional study shown as a baseline for national key indicators of neonatal health

of the deaths occurred in India, Pakistan, Nigeria, the Democratic Republic of Congo and Ethiopia. ${ }^{3}$ In the early neonatal period, NNJ was the seventh global cause of neonatal mortality, whereas it is also the seventh and eighth leading cause of death in Sub-Saharan Africa and South Asia, respectively. ${ }^{4-6}$ Severe NNJ accounted for $30.8 \%$ of neonatal deaths in India, ${ }^{7} 34 \%$ in Nigeria, ${ }^{8} 14 \%$ in Kenya ${ }^{9}$ and $6.7 \%$ in Egypt. ${ }^{10}$ In Ethiopia, the prevalence of NNJ was ranged from $37.3 \%$ to $44.9 \% .^{1112}$ NNJs also contributed to 242546 patients admitted to the neonatal intensive care unit in Taiwan ${ }^{13}$ and $16.67 \%-31.7 \%$ of hospital admissions and a case fatality rate of $32 \%$ in Ethiopia. ${ }^{14} 15$

NNJ prevention is important in the first week of life in Sub-Saharan Africa and South Asia, especially in the majority of the countries with the highest global burden of neonatal mortality. ${ }^{5}$ Postnatal mother's response about NNJ depends on their knowledge on NNJ and what innate risk factors could cause a complication if not appropriately treated in their newborns. Lack of enough information or wrong information about NNJ may explain as a cause for poor decision and delayed to seek medical care. ${ }^{16-20}$ 
Early detection and treatment are the key strategies to prevent severe NNJ. An understanding of the knowledge level of mothers on NNJs helps to identify the gaps and target areas for intervention which helps to prevent chronic morbidity and neonatal mortality. ${ }^{182122}$ Many of the risk factors of NNJs can be minimised if the mother knowledge on NNJs is improved, which ultimately helps to formulate and evolve strategies to identify high-risk cases and optimise management strategies to prevent newborn deaths and disability and reduce the incidence of NNJ. ${ }^{16} 1921$ Despite the identification of severe NNJ as a global health problem, progress towards its elimination has been slow. Prevalence of the disease remains high globally and locally. No previous research has looked at the knowledge about jaundice among mothers in Ethiopia. Therefore, this study aimed to assess knowledge on NNJ among mothers in referral hospitals of Amhara region, northern Ethiopia. The information obtained could be used to assist healthcare providers and policymakers in designing educational programmes to improve the knowledge on NNJ among mothers in Ethiopia.

\section{METHODS}

\section{Study setting and design}

The facility-based cross-sectional study design was conducted from 1 March to 30 July at referral hospitals in the Amhara region, northern Ethiopia, 2019. The Amhara region has a total of six referral hospitals: Felegehiwot referral hospital, University of Gondar referral hospital, Debre Markos referral hospital, Debre Birhan referral hospital and Dessie referral hospital.

\section{Source and study population}

The source population was all mothers who gave birth at referral hospitals in the Amhara region. All mothers who gave birth and whose neonates were admitted to the neonatal intensive care unit at selected health facilities during the study period were included in the study.

\section{Inclusion and exclusion criteria}

Mothers who gave birth in the selected health facilities were included in this study, whereas mothers who have been getting serious illness were excluded from the study.

\section{Sample size determination and sampling procedure}

The sample size was determined by using Epi info 7 software using a single population proportion formula with the assumption of $95 \% \mathrm{CI}, \mathrm{p}=$ mothers knowledge on NNJ in Holy Karbala City, Iraq $(\mathrm{p}=34 \%),{ }^{23} \mathrm{~d}=$ is a tolerable margin of error $(d=0.05)$ and $10 \%$ non-response rate, the final sample size for the study is 380 . The total sample size was proportionally allocated to the size of the population for each hospital depending on the 3 month patient flow in the neonatal intensive care unit. The average estimated number of mothers who gave birth in referral hospitals in the Amhara region for 3 months was taken. Accordingly, the calculated sample was distributed into all health facilities proportional to the size of mothers giving birth in these 3 months' time. Finally, a systematic random sampling technique was used to include participants in the study.

\section{OPERATIONAL DEFINITIONS \\ Attitude on NNJ}

Those mothers who scored mean and above on questions to assess the attitude of mothers about NNJ were labelled as having a favourable attitude and those who scored below the mean value were labelled as having unfavourable attitude. ${ }^{18}$

\section{Knowledge on NNJ}

Those mothers who scored mean and above on questions to assess comprehensive knowledge on NNJ were labelled as having good knowledge and those who scored below the mean value were labelled as having poor knowledge. ${ }^{24}$

\section{Methods of data collection tools and procedures}

Data were collected by interviews with the mothers. The questions are both open and close-ended. The questionnaire addressed the women's socio-demographic characteristics, obstetrics-related characteristics and knowledge and attitude-related characteristics. The data collectors collected an institution-based face-to-face interview by using the pretested structured Amharic questionnaire. The English language questionnaire was translated into the Amharic language (a language spoken in the study area) and was translated back to the English language, a comparison was made on the consistency of the two versions. The knowledge assessment tool was adapted from a study done in Nepal, Ghana, Nigeria and Malaysia. ${ }^{16} 182021$ 25-27 Knowledge on NNJ was assessed by 25 reliable items (Cronbach's alpha $=0.81)^{28}$ (items on ever heard of jaundice, source of information, body parts involved, danger signs, cause, complications, treatment and prevention of NNJ), and Mother's attitude NNJ was assessed by seven attitude related items consisting of 5-point Likert scale.(Cronbach's alpha $=0.78$ ). The interviewers collected the data in the postnatal period at the time of admission of neonates in the neonatal intensive care unit after informing the postnatal mothers about the details of the research. The mothers were encouraged to feel free and told that the confidentiality of their responses was assured and no information was shared with third parties, except the investigator. Onsite supervision was carried out when the data were collected daily by the supervisors. At the end of each day, questionnaires were reviewed and cross-checked for completeness, accuracy and consistency by the supervisor and principal investigator, and corrective measures were taken.

\section{Data quality control}

The training was given for data collectors and supervisors for 2 days about the techniques of data collection and briefed on each question included in the data collection 
Table 1 Socio-demographic characteristics of mothers in northern Ethiopia, 2019 ( $n=380)$

\begin{tabular}{|c|c|c|c|}
\hline Characteristics & Category & Frequency & $\%$ \\
\hline \multirow[t]{2}{*}{ Mothers age (years) } & $<20$ & 43 & 11.3 \\
\hline & 20-35 & 316 & 83.2 \\
\hline \multirow[t]{2}{*}{ Marital status } & Married & 359 & 94.5 \\
\hline & Others ${ }^{*}$ & 21 & 5.5 \\
\hline \multirow{2}{*}{ Religion } & Muslim & 100 & 26.3 \\
\hline & Otherst & 5 & 1.3 \\
\hline \multirow[t]{3}{*}{ Ethnicity } & Amhara & 349 & 91.8 \\
\hline & Oromo & 28 & 7.4 \\
\hline & Others $\ddagger$ & 3 & 0.8 \\
\hline \multirow{3}{*}{ Mothers education } & Primary education & 86 & 22.6 \\
\hline & Secondary education & 89 & 23.4 \\
\hline & College and above & 82 & 21.6 \\
\hline \multirow[t]{6}{*}{ Occupation of the mother } & Housewife & 200 & 52.6 \\
\hline & Government employee & 71 & 18.7 \\
\hline & Daily workers & 17 & 4.5 \\
\hline & Farmer & 29 & 7.6 \\
\hline & Student & 28 & 7.4 \\
\hline & Others§ & 35 & 9.2 \\
\hline
\end{tabular}

${ }^{*}$ Divorced, single.

†Protestant, catholic.

¥SNNP, Tigray.

§Private employee, merchant.

tool. The pretest was conducted in $5 \%$ of the total sample size to ensure the validity of the tool, then the correction was made before the actual data collection started. To minimise bias, interviews were conducted in an area with adequate confidentiality and privacy. Proper coding and categorisation of data were maintained for the quality of the data to be analysed. Double data entry was done by two data clerks and the consistency of the entered data was cross-checked by comparing the two separately entered data.

\section{Data processing and analysis}

The data was coded, cleaned, edited and entered into Epi data V.4.2 and exported to SPSS window V.24 for analysis. Summary statistics (mean or median) for continuous variables and percentage and frequency for categorical variables were computed. The bivariable analysis was used to see the association between each independent variable and the outcome variable by using binary logistic regression. The goodness of fit was tested by Hosmer-Lemeshow statistic and Omnibus tests. All variables with $\mathrm{p} \leq 0.25$ in the bivariable analysis were included in the final model of multivariable analysis to control all possible confounders. The direction and strength of statistical associations were measured by the OR with $95 \%$ CI. The adjusted OR along with $95 \%$ CI was estimated and $p$ value $<0.05$ was set as a cut-off point for the significant association with knowledge of $\mathrm{NNJ}$.

\section{Patient and public involvement}

In this study, the patient and/or the public were not involved in the design, development, analysis and publication of this study.

\section{RESULTS}

\section{Socio-demographic characteristics}

In this study, a total of 380 mothers were involved, making the overall response rate of $100 \%$. The mean age of the mother was $26.89( \pm 5.05 \mathrm{SD})$ years. More than four-fifths of mothers were within the age group between 20 and 35 years. And most of all, 359 (94.5\%) were married, and 
Table 2 Obstetrics characteristics of mothers in northern Ethiopia, $2019(n=380)$

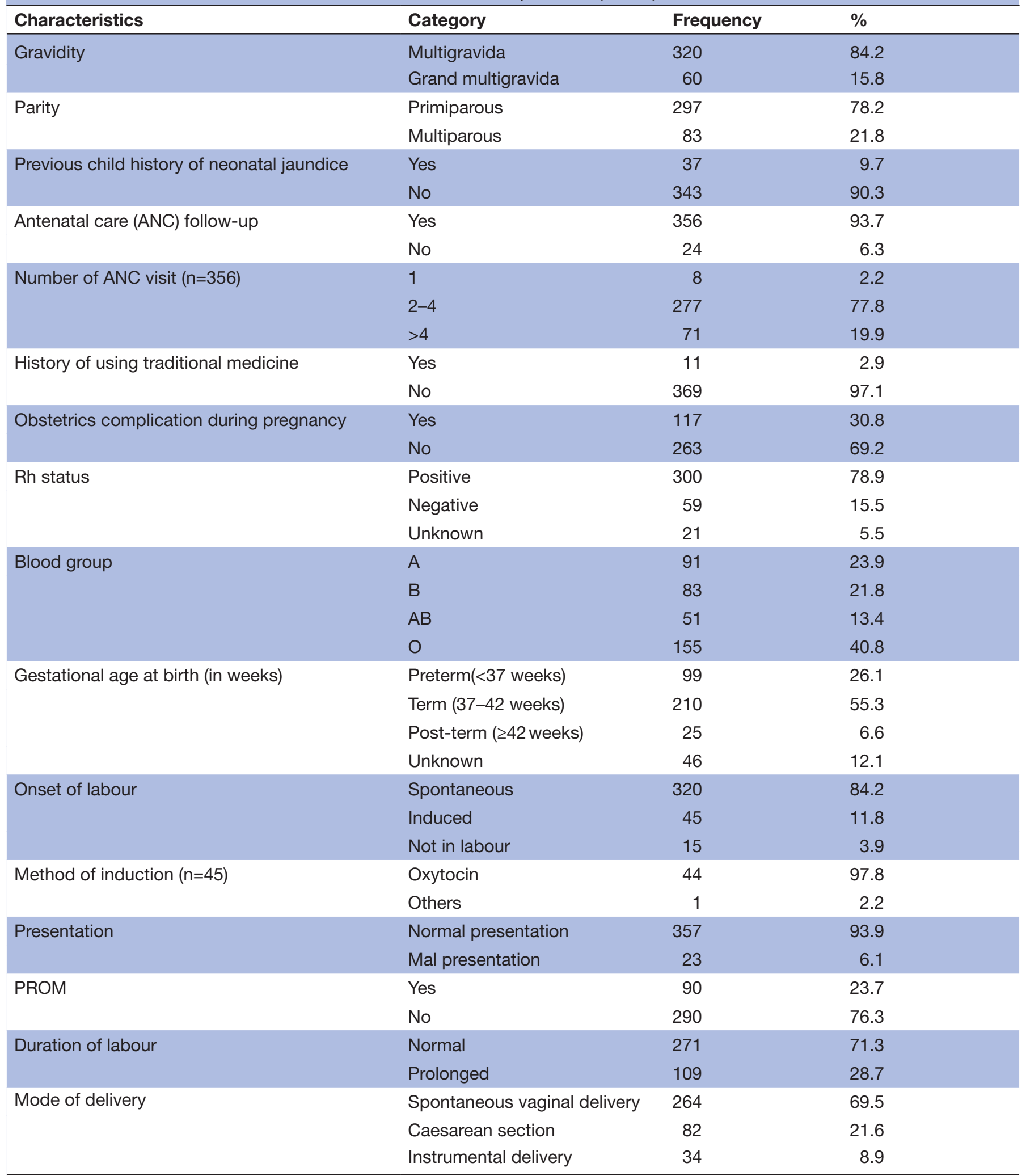

PROM, Premature rupture of membrane .

349 (91.8\%) were Amhara in ethnic. Regarding educational status, $82(21.6 \%)$ were college and above level, and $200(52.6 \%)$ were housewives. More than two-thirds,
$265(69.7 \%)$ of mothers were resided in the urban areas (table 1). 
Mother's knowledge on neonatal jaundice

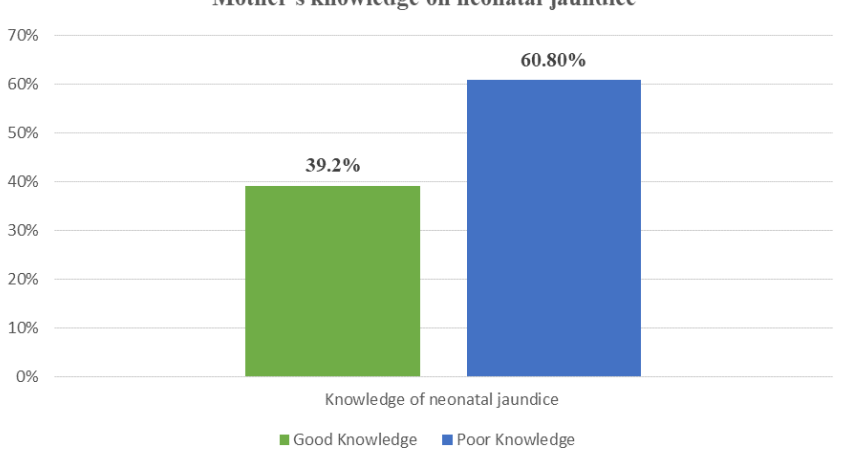

Figure 1 Mother's knowledge on neonatal jaundice in northern Ethiopia, 2019.

\section{Obstetrics-related characteristics of mothers}

The mean gestational age of the mother at birth $( \pm \mathrm{SD})$ was $38.31( \pm 2.4)$ weeks. Regarding birth history, 320 $(84.2 \%)$ and $297(78.2 \%)$ of mothers were multigravida and primiparous, respectively. Concerning the utilisation of antenatal care (ANC) utilisation, almost all $356(93.7 \%$ ) mothers had a history of ANC follow-up, of them more than three-fourths, $277(77.8 \%)$ of mothers had 2-4 ANC visits during their recent pregnancy. Regarding the mode of delivery, more than two-thirds, 264 (69.5\%) delivered via spontaneous vaginal delivery, and 271 (71.3\%) had a normal duration of labour. Related to blood group and Rh status, 155 (40.8\%), and 300 (78.9\%) of the mothers had ' $\mathrm{O}$ ' blood group and positive $\mathrm{Rh}$ status, respectively (table 2).

\section{Mother's knowledge on NNJ}

Comprehensive knowledge of NNJ was computed by summing up all relevant 10 questions (25 knowledge items on ever heard jaundices, source of information, body parts involved, danger signs, cause, complications, treatment and prevention of NNJ). A correct answer for each item was scored as ' 1 ' and an incorrect answer was scored as ' 0 '. Items were then summed up and the mean score was calculated. Finally, those respondents who scored mean and above were labelled as having good knowledge, and those scoring below the mean

Mother's attitude on neonatal jaundice

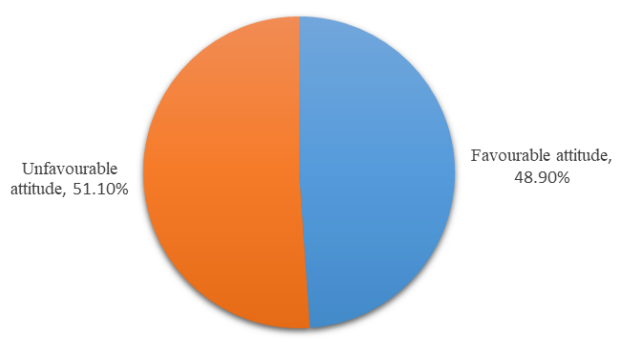

- Favourable attitude = Unfavourable attitude

Figure 2 Mother's attitude on neonatal jaundice in northern Ethiopia, 2019. were labelled as having poor knowledge. In this study, the overall good knowledge of mothers about NNJ was $39.2 \%(95 \%$ CI: $34.0 \%$ to $44.2 \%)$ (figure 1$)$. The knowledge of women about NNJ regarding parity, 120 $(40.4 \%)$ of primiparous and $29(34.9 \%)$ of multiparous mothers had good knowledge. In addition, 139 (38.9\%) of mothers who delivered through normal presentation and $10(43.5 \%)$ of mothers who had malpresentation had good knowledge about NNJ.

\section{Mother's attitude on NNJ}

The attitude of mother's towards NNJ was computed by summing up all relevant seven attitude-related items consisting of a 5-point Likert scale. All responses were marked using a 5-point Likert scale. The 7-item instrument Likert scale with a score range of 7-35. Finally, those respondents who scored mean and above were labelled as having a favourable attitude, and those scoring below the mean were labelled as having an unfavourable attitude. In this study, $186(48.9 \%)$ had a favourable attitude whereas $194(51.1 \%)$ had an unfavourable attitude towards NNJ (figure 2).

\section{Factors associated with mother's knowledge on NNJ}

In the bivariable binary logistic regression analysis, educational level of the mother, age of the mother, occupation of the mother, mother attitude about NNJ, previous child history of NNJ, current child history of NNJ, obstetrics complications, duration of labour, ANC follow-up and residence were variables showing significant association on bivariable analysis at a $p$ value of $\leq 0.25$ to control (adjust) the possible confounding in the multivariable binary logistic regression model. After adjustment, mother attitude on NNJ, previous child history of NNJ, current child history of NNJ, ANC follow-up and residence were variables that had a significant association with knowledge of mothers on NNJ at $p$ value $<0.05$ in multivariable analysis.

Mothers having a favourable attitude were two times more likely to have good knowledge compared with mothers having unfavourable knowledge about NNJ $(\mathrm{AOR}=2.05,95 \% \mathrm{CI}: 1.25$ to $3.34, \mathrm{p}=0.004)$. The odds of knowledge on NNJ among mothers who had a history of NNJ in previous children were 7.5 times higher compared with their counterparts $(\mathrm{AOR}=7.51,95 \% \mathrm{CI}$ : 3.12 to 18.05 , $\mathrm{p}<0.001)$.

The findings of this study showed that mothers who had a history of NNJ in the current child were almost two times more likely knowledgeable as compared with their counterparts $(\mathrm{AOR}=1.97,95 \% \mathrm{CI}$ : 1.19 to $3.27, \mathrm{p}=0.008)$. In addition, mothers who had ANC follow-up were 3.85 times more likely to have good knowledge about NNJ as compared with mothers who had not ANC follow-up (AOR=3.85, 95\% CI: 1.24 to $14.55, \mathrm{p}=0.04)$. Similarly, those mothers who resided in the urban areas were 2.63 times more likely to have good knowledge as compared with mothers who resided in the rural area $(\mathrm{AOR}=2.63$, 95\% CI: 1.32 to $5.25, \mathrm{p}=0.006$ ) (table 3 ). 
Table 3 Factors associated with knowledge on neonatal jaundice (NNJ) among mothers in northern Ethiopia, $2019(n=380)$

\begin{tabular}{|c|c|c|c|c|}
\hline \multirow[b]{2}{*}{ Characteristics } & \multicolumn{2}{|c|}{ Knowledge of NNJ } & \multirow[b]{2}{*}{ COR $(95 \% \mathrm{Cl})$} & \multirow[b]{2}{*}{ AOR $(95 \% \mathrm{Cl})$} \\
\hline & Good (\%) & Poor (\%) & & \\
\hline \multicolumn{5}{|l|}{ Mothers age (years) } \\
\hline$<20$ & $12(27.9)$ & $31(72.1)$ & 1 & 1 \\
\hline 20-35 & $130(41.1)$ & $186(58.9)$ & 1.80 (0.89 to 3.64$)$ & 1.01 (0.46 to 2.24$)$ \\
\hline$>35$ & $7(33.3)$ & $14(66.7)$ & 1.29 (0.42 to 3.98$)$ & 0.61 (0.15 to 2.39$)$ \\
\hline \multicolumn{5}{|l|}{ Mothers education } \\
\hline No formal education & $39(31.7)$ & $84(68.3)$ & 1 & 1 \\
\hline Primary education & $33(38.4)$ & $53(61.6)$ & 1.34 (0.75 to 2.39$)$ & 1.21 (0.59 to 2.47$)$ \\
\hline Secondary education & $29(32.6)$ & $60(67.4)$ & 1.04 (0.58 to 1.87$)$ & 0.76 (0.35 to 1.65$)$ \\
\hline College and above & $48(58.5)$ & $34(41.5)$ & 3.04 (1.70 to 5.43$)$ & 1.22 (0.41 to 3.59$)$ \\
\hline \multicolumn{5}{|l|}{ Mothers occupation } \\
\hline Housewife & $69(34.5)$ & $131(65.5)$ & 1.01 (0.44 to 2.27$)$ & $0.42(0.15$ to 1.16$)$ \\
\hline Government employee & $45(63.4)$ & $26(36.6)$ & 3.29 (1.33 to 8.13$)$ & 1.38 (0.35 to 5.58$)$ \\
\hline Daily workers & $5(29.4)$ & $12(70.6)$ & 0.79 (0.22 to 2.89$)$ & 0.48 (0.11 to 2.22$)$ \\
\hline Farmer & $10(34.5)$ & $19(65.5)$ & 1 & 1 \\
\hline Student & $8(28.6)$ & $20(71.4)$ & 0.99 (0.35 to 2.79$)$ & 0.44 (0.13 to 1.55$)$ \\
\hline Others* & $12(34.3)$ & $23(65.7)$ & 0.76 (0.25 to 2.33$)$ & 0.54 (0.13 to 2.16$)$ \\
\hline \multicolumn{5}{|l|}{ Attitude towards NNJ } \\
\hline Favourable & $89(47.8)$ & $97(52.2)$ & 2.04 (1.35 to 3.12$)$ & $2.05(1.25 \text { to } 3.34)^{\star}$ \\
\hline Unfavourable & 60 (30.9) & $134(69.1)$ & 1 & 1 \\
\hline \multicolumn{5}{|l|}{ Previous child history of NNJ } \\
\hline Yes & $29(78.4)$ & $8(21.6)$ & 4.23 (2.02 to 8.85$)$ & $7.51(3.12 \text { to } 18.05)^{\star \star}$ \\
\hline No & $120(35.0)$ & $223(65.0)$ & 1 & 1 \\
\hline \multicolumn{5}{|l|}{ Obstetrics complication } \\
\hline Yes & $54(46.2)$ & $63(53.8)$ & $1.52(0.97$ to 2.36$)$ & 0.99 (0.59 to 1.66$)$ \\
\hline No & $95(36.1)$ & 168 (63.9) & 1 & 1 \\
\hline \multicolumn{5}{|l|}{ Current baby jaundiced } \\
\hline Yes & $61(50.4)$ & $60(49.6)$ & 1.98 (1.27 to 3.07$)$ & $1.97(1.19 \text { to } 3.27)^{\star * *}$ \\
\hline No & $88(34.0)$ & $171(66.0)$ & 1 & 1 \\
\hline \multicolumn{5}{|l|}{ ANC follow-up } \\
\hline Yes & $146(41.0)$ & $210(59.0)$ & 4.86 (1.42 to 16.62$)$ & $3.85(1.24 \text { to } 14.55)^{\star \star \star \star}$ \\
\hline No & $3(12.5)$ & $21(87.5)$ & 1 & 1 \\
\hline \multicolumn{5}{|l|}{ Residence } \\
\hline Urban & $115(43.4)$ & $150(56.6)$ & 2.35 (1.45 to 3.81$)$ & $2.63(1.32 \text { to } 5.25)^{\star \star \star \star \star}$ \\
\hline Rural & 34 (29.6) & $81(70.4)$ & 1 & 1 \\
\hline
\end{tabular}

Significant at: ${ }^{*} \mathrm{p}=0.004,{ }^{* \star} \mathrm{p}<0.001,{ }^{\star \star \star} \mathrm{p}=008,{ }^{* \star \star \star} \mathrm{p}=0.04,{ }^{\star \star \star \star \star} \mathrm{p}=0.006,1=$ constant.

COR, crude odds ratio.

\section{DISCUSSION}

NNJ is one of the most common disorders resulting in severe neurological sequelae globally and nationally. Timely and proper management to reduce these complications depends on the level of the mother's knowledge about NNJ. This study sought to assess the level of maternal knowledge about NNJ and identify the possible factors associated with mother's knowledge on $\mathrm{NNJ}$ at referral hospitals in the Amhara region, northern
Ethiopia. The overall mother's knowledge on NNJ was $39.2 \%$. This finding was in line with a study conducted in Karbala city, Iraq (34\%). ${ }^{23}$ However, it was lower than the study conducted in Egypt, $52.3 \%,{ }^{29}$ Sagamu, Southwest Nigeria, $57.1 \%,{ }^{26}$ Baghdad, Iraq, $71 \%{ }^{24}$ and Tabriz, Iran, $77 \% .^{22}$ The difference might be due to the time gap between the studies and differences in sociodemographic characteristics of study participants. It was higher than a study conducted in Malaysia $7.4 \%{ }^{27}$ and Nepal $22 \% .{ }^{25}$ 
This might be due to currently increasing information on NNJ for mothers and our study had predominantly urban mothers among which showed a strong association with mother knowledge on NNJ.

This study revealed that mothers who had a favourable attitude on NNJ were more likely knowledgeable compared with mothers who had an unfavourable attitude. This finding was supported by a study conducted in Egypt ${ }^{29}$ Iran. ${ }^{20}$ This might be due to the fact that those mothers who had a favourable attitude towards NNJ would have good knowledge.

This study also revealed that having a history of jaundice in current and previous children was significantly associated with the mother's knowledge on NNJ. The odds of knowledge on NNJ among mothers who had a history of $\mathrm{NNJ}$ in previous children was higher compared with their counterparts. This finding was in line with studies conducted in Iran, ${ }^{20}$ Benin City, Nigeria, ${ }^{21}$ Malaysia $^{27}$ and Thailand-Myanmar. ${ }^{30}$ Similarly, mothers who had a history of NNJ in the current child were more likely knowledgeable as compared with their counterparts. This might be due to the fact that most of these cases are likely to have received treatment and mothers might get information regarding the treatment and prevention of complications from NNJ which may, in turn, raise their awareness of NNJ.

Having ANC follow-up was also another determinant factor for knowledge on NNJ. Mothers who had had ANC follow-up were more likely knowledgeable on NNJ as compared with those mothers who had not ANC follow-up. This finding was supported by a study done in Lagos, Nigeria. ${ }^{18}$ This might be due to the fact that mothers who had ANC follow-up might get information about the danger signs of newborns and decide to give birth in health institutions that would help the mother to get adequate information about NNJ. Additionally, those mothers who were from urban residents were more likely knowledgeable as compared with those mothers who came from the rural area. This finding was in line with a study conducted in Egypt. ${ }^{29}$ This might be due to the fact that urban residents have more information and access to mass media and might have good healthcare-seeking behaviour for the encountered problems of the newborn.

\section{CONCLUSION}

The overall knowledge of mothers on NNJ was low. This study showed that the mother's attitude on NNJ, child history of NNJ, current child history of NNJ, ANCfollow-up, and residence were variables that had a significant association with mother's knowledge on NNJ. Enhancing NNJ educational programmes targeting mothers, with an emphasis on raising attitudes, incorporating health education among mothers who came for ANC follow-up and resided in a rural area could help in increasing the awareness about the prevention of $\mathrm{NNJ}$ in the population. In addition, timely diagnosis and immediate intervention to minimise its progression to the more debilitating stage of kernicterus and decrease the accompanying mortality as well as continuing neurological impairments through aversion of late presentation of NNJ cases in the hospital are the recommended interventions.

Acknowledgements We would like to acknowledge Woldia University for full funding of the research. Our appreciation also goes to the Amhara Region Health Bureau human resource for giving us the necessary information needed to conduct this study. We also thank the managers, medical directors and staffs of the referral hospitals for giving the necessary information needed to conduct this study. Authors are also grateful for data collectors, supervisors and study subjects.

Contributors $A D$ was the principal investigator who initiated the research, wrote the research proposal, conducted the fieldwork, supervised data entry, analysed the data and wrote the manuscript. All authors (AD, AG, AW, BA and GG) critically reviewed, provided substantive feedback and contributed to the intellectual content of this paper, and made substantial contributions to the conception, conceptualisation and manuscript preparation of this study. All authors read and approved the final manuscript.

Funding The authors have not declared a specific grant for this research from any funding agency in the public, commercial or not-for-profit sectors.

Competing interests None declared.

Patient and public involvement Patients and/or the public were not involved in the design, or conduct, or reporting, or dissemination plans of this research.

Patient consent for publication Not required.

Ethics approval Ethical clearance was obtained from Woldia University, College of Health Sciences; institutional health research ethics review committee (IHRERC). A formal letter for permission and support was written to Amhara Regional Health Bureau (ARHB) from Woldia University and finally to selected health facilities. All study participants were informed about the purpose of the study, their right to refuse. In the study, all mothers were above the age of 18 , as a result, written and signed voluntary consent was obtained from them before distributing the questionnaire. The respondents were also told that the information obtained from them was treated with complete confidentiality and did not cause any harm to them.

Provenance and peer review Not commissioned; externally peer reviewed.

Data availability statement All data relevant to the study are included in the article or uploaded as supplementary information.

Open access This is an open access article distributed in accordance with the Creative Commons Attribution Non Commercial (CC BY-NC 4.0) license, which permits others to distribute, remix, adapt, build upon this work non-commercially, and license their derivative works on different terms, provided the original work is properly cited, appropriate credit is given, any changes made indicated, and the use is non-commercial. See: http://creativecommons.org/licenses/by-nc/4.0/.

\section{ORCID iDs}

Asmamaw Demis http://orcid.org/0000-0003-4127-8642

Addisu Getie http://orcid.org/0000-0002-0572-3414

Adam Wondmieneh http://orcid.org/0000-0002-3986-8072

Birhan Alemnew http://orcid.org/0000-0003-1066-9798

\section{REFERENCES}

1 American Academy of Pediatrics. Clinical practice guideline; management of hyperbilirubinemia in the newborn infant 35 or more weeks of gestation; 2004.

2 Greco C, Arnolda G, Boo N-Y, et al. Neonatal jaundice in lowand middle-income countries: lessons and future directions from the 2015 Don Ostrow Trieste yellow retreat. Neonatology 2016;110:172-80.

3 Liu L, Oza S, Hogan D, et al. Global, regional, and national causes of under-5 mortality in 2000-15: an updated systematic analysis with implications for the sustainable development goals. The Lancet 2016;388:3027-35.

4 Slusher TM, Zamora TG, Appiah D, et al. Burden of severe neonatal jaundice: a systematic review and meta-analysis. BMJ Paediatr Open 2017;1:e000105.

5 Olusanya BO, Teeple S, Kassebaum NJ. The contribution of neonatal jaundice to global child mortality: findings from the GBD 2016 study. 
Pediatrics 2018;141. doi:10.1542/peds.2017-1471. [Epub ahead of print: 0501 2018].

6 Wang $\mathrm{H}$, Abajobir AA, Abate $\mathrm{KH}$, et al. Global, regional, and national under-5 mortality, adult mortality, age-specific mortality, and life expectancy, 1970-2016: a systematic analysis for the global burden of disease study 2016. The Lancet 2017;390:1084-150.

7 Slusher TM, Zamora TG, Appiah D, et al. Burden of severe neonatal jaundice: a systematic review and meta-analysis. BMJ Paediatr Open 2017; 1:e000105

8 Eneh AU, Oruamabo RS. Neonatal jaundice in a special care baby unit (SCBU) in Port Harcourt, Nigeria: a prospective study. Port Harcourt Medical Journal 2008;2:110-7.

9 Mwaniki MK, Gatakaa HW, Mturi FN, et al. An increase in the burden of neonatal admissions to a rural district hospital in Kenya over 19 years. BMC Public Health 2010;10:591.

10 Iskander I, Gamaleldin R, El Houchi S, et al. Serum bilirubin and bilirubin/albumin ratio as predictors of bilirubin encephalopathy. Pediatrics 2014;134:e1330-9.

11 Lake EA, Abera GB, Azeze GA, et al. Magnitude of neonatal jaundice and its associated factor in neonatal intensive care units of Mekelle City public hospitals, Northern Ethiopia. Int J Pediatr 2019;2019:1-9.

12 Kassa RT, Gudeta H, Assen ZM, et al. Neonatal hyperbilirubinemia: magnitude and associated etiologic factors among neonates admitted at Tikur Anbessa specialized Hospital, Ethiopia. Journal of Pregnancy and Child Health 2018;05.

13 Tsao P-C, Yeh H-L, Chang Y-C, et al. Outcomes of neonatal jaundice in Taiwan. Arch Dis Child 2018;103:927-9.

14 Tewabe T, Mehariw Y, Negatie E, et al. Neonatal mortality in the case of Felege Hiwot referral Hospital, Bahir Dar, Amhara regional state, North West Ethiopia 2016: a one year retrospective chart review. Ital $J$ Pediatr 2018:44:57.

15 Kokeb M, Desta T. Institution based prospective cross-sectional study on patterns of neonatal morbidity at Gondar university hospital neonatal unit, north-west Ethiopia. Ethiop J Health Sci 2016;26:73.

16 Adoba P, Ephraim RKD, Kontor KA, et al. Knowledge level and determinants of neonatal jaundice: a cross-sectional study in the Effutu Municipality of Ghana. Int J Pediatr 2018;2018:1-9.

17 Olusanya BO, Osibanjo FB, Mabogunje CA, et al. The burden and management of neonatal jaundice in Nigeria: a scoping review of the literature. Niger J Clin Pract 2016;19:1.
18 Goodman OO, Kehinde OA, Odugbemi BA, et al. Neonatal jaundice: knowledge, attitude and practices of mothers in Mosan-Okunola community, Lagos, Nigeria. Niger Postgrad Med J 2015;22:158-63.

$19 \mathrm{Ng}$ SY, Chong SY. What do mothers know about neonatal jaundice? knowledge, attitude and practice of mothers in Malaysia. Med $\mathrm{J}$ Malaysia 2014;69:252-6.

20 Khalesi N, Rakhshani F. Knowledge, attitude and behaviour of mothers on neonatal jaundice. J Pak Med Assoc 2008;58:671-4.

21 Egube BA, Ofili AN, Isara AR, et al. Neonatal jaundice and its management: knowledge, attitude, and practice among expectant mothers attending antenatal clinic at University of Benin Teaching Hospital, Benin City, Nigeria. Niger J Clin Pract 2013;16:188-94.

22 Amirshaghaghi A, Ghabili K, Shoja MM, et al. Neonatal jaundice: knowledge and practice of Iranian mothers with icteric newborns. Pak J Biol Sci 2008;11:942-5.

23 Hussein H, Aziz A. Assessment of mothers' knowledge and beliefs toward care of neonatal jaundice in pediatric teaching hospital in Holy Karbala City. Int J Sci Res 2016;6 http://www.ijsrp.org/researchpaper-0916.php?rp=P575824

24 ThabitMF, F Thabit M, F Thabit M. Knowledge regarding neonatal jaundice among a sample of mothers attending some primary health care centers /Baghdad. Diyala Journal of Medicine 2019;17:77-84.

25 Shrestha S, Maharian S, Petrini M. Knowledge about neonatal jaundice among Nepalese mothers. JBPKIHS 2019;2:34-42.

26 Ogunlesi TA, Abdul AR. Maternal knowledge and care-seeking behaviors for newborn jaundice in Sagamu, Southwest Nigeria. Niger $J$ Clin Pract 2015;18:33-40.

27 Boo NY, Gan CY, Gian YW, et al. Malaysian mothers' knowledge \& practices on care of neonatal jaundice. Med J Malaysia 2011;66:239-43.

28 Tavakol M, Dennick R. Making sense of Cronbach's alpha. Int J Med Educ 2011;2:53-5.

29 Moawad EMI, Abdallah EAA, Ali YZA. Perceptions, practices, and traditional beliefs related to neonatal jaundice among Egyptian mothers: a cross-sectional descriptive study. Medicine 2016;95:e4804.

30 Prins TJ, Trip-Hoving M, Paw MK, et al. A survey of practice and knowledge of refugee and migrant pregnant mothers surrounding neonatal jaundice on the Thailand-Myanmar border. J Trop Pediatr 2017;63:50-6. 